\title{
T21 JAMAICA: A TOOL FOR LONG-TERM SUSTAINABLE DEVELOPMENT PLANNING
}

\author{
W. QU ${ }^{1}$, H. MORRIS ${ }^{2} \&$ J. SHILLING ${ }^{1}$ \\ ${ }^{1}$ Millennium Institute, USA. \\ ${ }^{2}$ Planning Institute of Jamaica, Jamaica.
}

\begin{abstract}
In formulating its long-term (2006-2030) national sustainable development plan, the Government of Jamaica chose the Threshold 21 (T21) model as an analytical tool to integrate economic, social, and environmental sectors in order to better comprehend the interactions among critical factors so they could: (1) better analyze the challenges Jamaica faces, (2) understand the medium and long-term consequences of alternative policy choices across all three sectors, and (3) determine the optimal combination of policies to achieve their strategic goals. Major challenges confronting Jamaica include slow GDP growth, lack of technical innovation, high unemployment, HIV/AIDS, crime, energy dependence, and natural disasters. The model shows how adopting a combination of policies including supporting education and infrastructure, providing micro credit to the poor, reducing crime and HIV infection, investing in promising new products, and attracting more remittances and foreign direct investment, would lead to a future, that is, possible and that is notably better than the business as usual scenario. Two other scenarios are also considered that address: (1) simpler social improvement policies in education, health, and welfare and (2) the impacts of natural disasters and the possible increase in the price of oil. Comparisons among scenarios are made in economic, social, and environmental areas, which include GDP, government revenues, demographic trends, unemployment, poverty, adult literacy rate, HIV adult prevalence rate, land use, water demand and pollution, and energy consumption (which is the major source of greenhouse gas emissions in Jamaica). They demonstrate how purely social policies are much less effective, even in the social sectors over the longer time horizon than the good strategy which enables more overall growth. The Government of Jamaica is currently using the model to support broad participation from both state and non-state stakeholders to reach consensus. T21 will also be used to monitor and evaluate progress in achieving the goals.

Keywords: monitoring and evaluation, national sustainable development, participatory policy making, scenario comparison, $T 21$ model.
\end{abstract}

\section{INTRODUCTION}

Jamaica is a Caribbean Island of $10,991 \mathrm{~km}^{2}$ with a population of 2.73 million. It is classified as a lower middle income developing country. Jamaica has abundant and diverse natural and human resources, and its people have recorded world class achievements in art, sports, and music. However, it has lagged behind its economic potential. Since 1962, annual real GDP growth has averaged $2.5 \%$ [1]. Per capita annual GDP growth is even lower, only $1.5 \%$, and about $15 \%$ of its population is living below the poverty line [2].

The Planning Institute of Jamaica (PIOJ) in 2006 started to lead and coordinate the national effort to prepare a long-term National Development Plan aimed at achieving developed country status by 2030 [3]. This Plan will build on previous Five Year Plans, the National Industrial Policy, and the Medium Term Policy Framework.

PIOJ selected the Threshold 21 (T21) model [4-6], developed by the Millennium Institute (MI), as the core tool to ensure that the Plan will be comprehensive in scope, integrate key sectors, and facilitate participation of all stakeholders. The model integrates a broad range of sectors in economic, environmental, and social areas; and its transparent structure and user-interface enables all stakeholders to engage in constructive dialogue about policy options, which helps achieve consensus. The model has been applied in more than 15 countries, and it has benefited from lessons learned 
along the line. In addition to building an effective country model, a major MI goal is to build the country team's technical capacity to a level where they can fully operate, update, and expand the model. They can take full responsibility for the model and assure its continued use.

In early 2006, PIOJ and MI began to develop the T21 Jamaica model. A team of three PIOJ technical staff was trained in System Dynamics modeling skills in a course run by MI at the University of Bergen. Once the team was trained and the relevant data collected, the senior MI modeler developed the initial version of the T21 Jamaica model, sector by sector, with cooperation and support from the PIOJ team, which was completed in January 2007. It was reviewed by a large group of interested parties, including government agencies, academics, and members of civil society. Many updates and additions to the model were then made by PIOJ and MI jointly, based on the reviewers' recommendations. After many improvements and extensions, the seventh version is currently supporting the Jamaica 2030 planning process, and the model is being maintained by the PIOJ technical team.

Section 2 introduces the base (business as usual) scenario of the country, showing the likely results of continuing current policies, problems that will arise, and the challenges faced in meeting the strategic goals for 2030. Section 3 explores possible policy choices to deal with the challenges and how a well designed combination of choices can help Jamaica achieve its strategic objectives. Section 4 then discusses how following some narrowly focused policy measures without attention to their indirect effects can lead to undesirable results. It also demonstrates how natural disasters could have adverse effects on Jamaica's long-term national development potential. Section 5 compares all these scenarios. Section 6 explains how the model is being used to support the long-term national planning process, and Section 7 summarizes progress to date and indicates the further research that is underway.

\section{OPPORTUNITIES AND CHALLENGES FACING JAMAICA: BASE SCENARIO}

In order to provide a reference for comparing alternative scenarios for long-term planning, we first generate a Base scenario with T21. Data from the historical period of 1990-2006 are used to calibrate the model, adjust parameters, and modify the underlying structure to make sure that the real relations of history are tracked as closely as possible by the model's structural relations. In doing this, results from the model may reveal data inconsistencies. This Base scenario replicates the major government policies and external conditions for the period 1990-2006, and then simulates Jamaica's development until 2030, assuming that the basic policy orientations and external conditions would not substantially change from the past (1990-2006).

By analyzing the key factors in the Base scenario results of the model and the underlying historical data, it is possible to demonstrate the achievements the country has made to date, and to better understand the reasons for any shortfalls from past objectives. Looking at the Base scenario out to 2030 and comparing the results with the country's strategic goals, it is possible to identify problems that will arise and the main challenges the country will face in the future in order to meet its strategic goals over the coming decades.

For example, since the 1970s, the Jamaica government has implemented a national family planning program which has achieved substantial success. The total fertility rate dropped from about five in the Seventies to below 2.5 in 2000 . The population growth has slowed, and the adult literacy rate has increased (not shown here). Figure 1 shows the historical data (Data) and the Base scenario (Base) for total population and total fertility rate, the close match indicates that the T21 model was able to replicate the historical data well. This helps validate the accuracy of the model's structure.

The graphs in Fig. 2 show the population pyramids for 1990 and 2005 to compare T21 results with actual data [7] (red represents historical data and blue represents T21 results). Analysis of the 

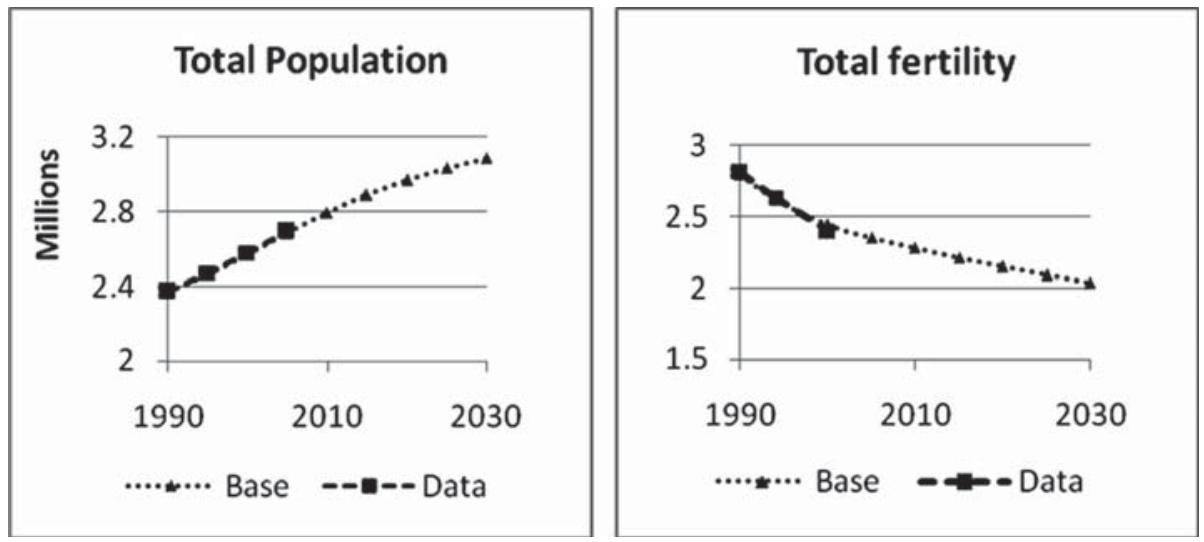

Figure 1: Comparing total population (a) and total fertility (b) with historical data.
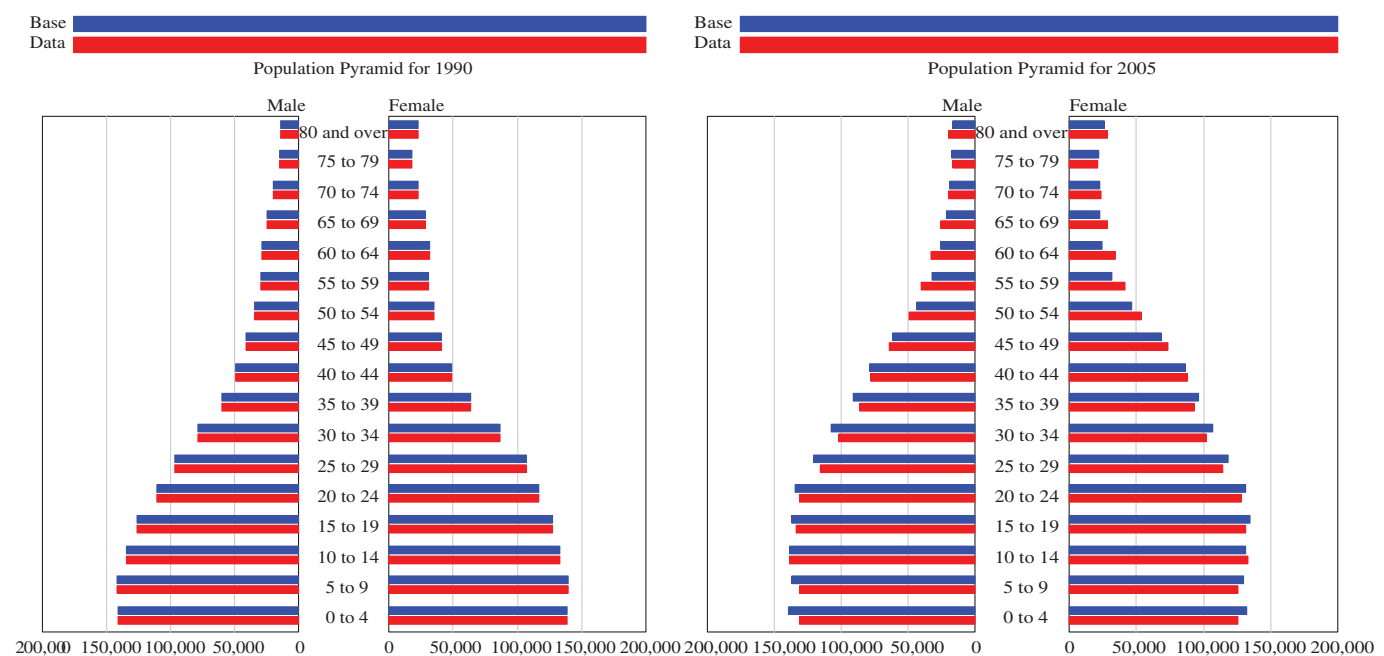

Figure 2: Comparing population age cohorts with historical data for 1990 (a) and 2005 (b).

slight mismatch between historical data and model results in Fig. $2 \mathrm{~b}$ revealed that the differences are partly due to data inconsistency (such as the number of people aged 5-9 in 1995 should be smaller than the number of people aged 0-4 in 1990, due to child mortality in the 5 years, but data showed the opposite). Currently, the Jamaica Statistical Office is working to eliminate the inconsistencies discovered by T21. One of the side benefits of the model is its contribution to improving the quality of country data.

This also illustrates how the model helps identify indirect effects of changes in variables: with the decrease of population growth and improvements in education, Jamaica will enjoy a higher quality of human resources and a decreasing Age Dependency Ratio (defined as the ratio of the non-labor age population to the labor age population). Other benefits of the policies to date have indicated that Jamaica has taken good care of its natural resources of land and water. About half of its land is still covered by forest (in thousands of hectares) (Fig. 3a), and the population has a high access to safe 


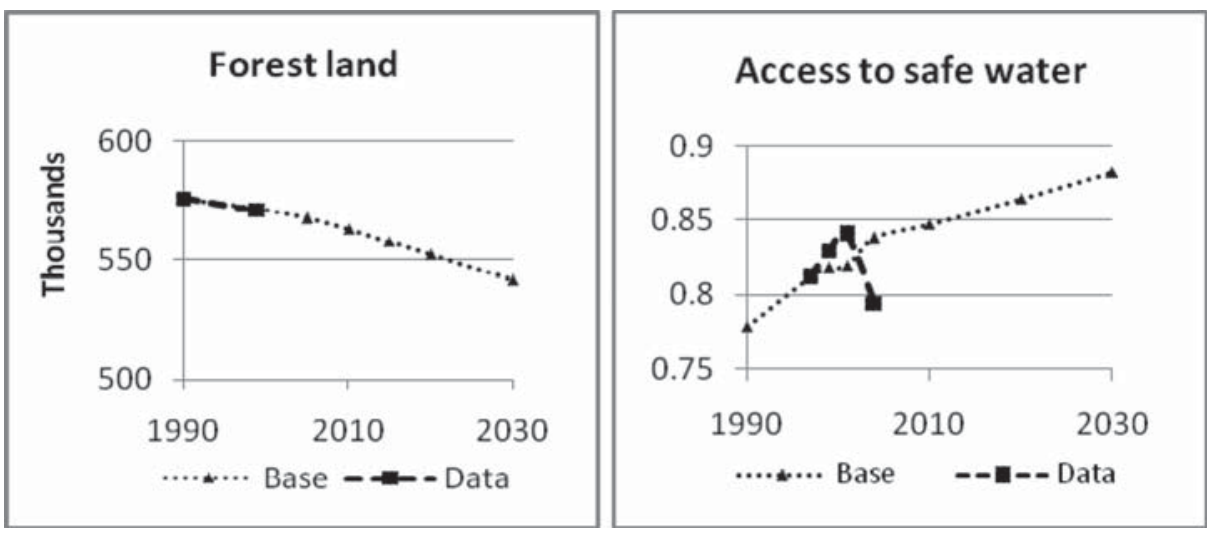

Figure 3: Comparing forest land (a) and access to safe water (b) with historical data.

water (percentage of population) (Fig. 3b). Data for access to safe water show some wide variation which is probably due to different survey methods used in different years.

In spite of all these achievements and many other favorable conditions, Jamaica is still facing considerable challenges in achieving its strategic goals. An analysis of the growth rates has helped identify several causes of these shortfalls in the past, both direct and indirect. These include the relatively low rates of returns on investment, dealing with a high level of debt, and the impacts of a relatively high level of crime on production and tourism. This analysis of the causes of past problems helps identify some of the challenges Jamaica will face in achieving its 2030 goals, especially in the following areas: unemployment, productivity improvements, HIV/AIDS, crime, energy demand and efficiency, and natural disasters.

The employment in industry and services (in thousands) are shown in Fig. 4. Given the policy of the past (Base scenario) both may increase moderately. The challenge is to create enough additional jobs to absorb workers from agriculture, plus the overall increase in the labor force.

The labor force, measured by the population size of age 15-59, will continue to grow (Fig. 5a). If all the people in the labor force want to work, and the employment opportunities are limited by the demand for workers, then the potential unemployment rate could be rather high, reaching $28-29 \%$, as shown in Fig. 5b. (Defined as the ratio of those in the working age population not working to the total labor force, some may not be seeking jobs.) Please note that there are no historical data in the graphs as none is available. The actual unemployment level will depend on the number of persons in the labor force who want to work. Generating enough employment to absorb the growing labor force is one of the main challenges facing the government in its longer term strategy to increase the standard of living and reduce a major cause of crime.

Industry and service production levels measured in real Jamaican currency are presented in Fig. 6.

Based on production values (Fig. 6) and employment numbers (Fig. 4), we can compute labor productivity, i.e. production per worker (not shown here). The stagnation, or even decline, of labor productivity, during 1990-2005 constitutes a major problem for the country. Without appropriate policy improvements, it will only rise slowly before $2030(<1.5 \%$ per year), which will constitute a serious obstacle for Jamaica to achieve its ambition of developed country status by 2030.

Other social issues that Jamaica has to deal with include the HIV/AIDS epidemic in the health sector and crime in the social relations sector, as shown in Fig. 7. (There are only two data points in Fig. 7a for 1990 and 2005.) In addition to HIV/AIDS's direct effects on the health and life expectancy of 

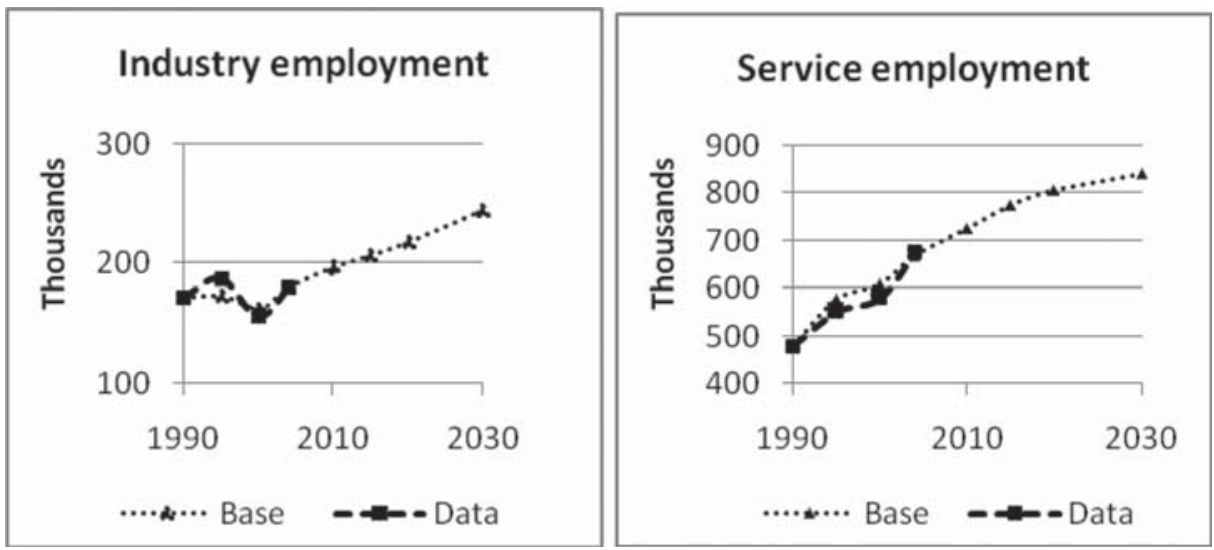

Figure 4: Comparing industry (a) and service (b) employments with historical data.
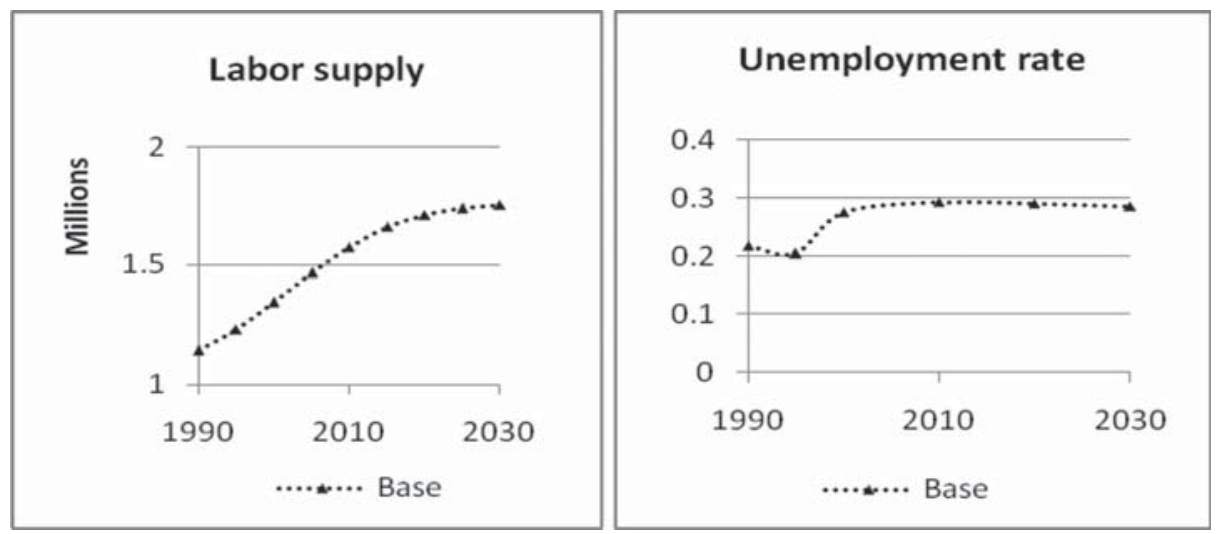

Figure 5: Labor supply (a) and potential unemployment rate (b).

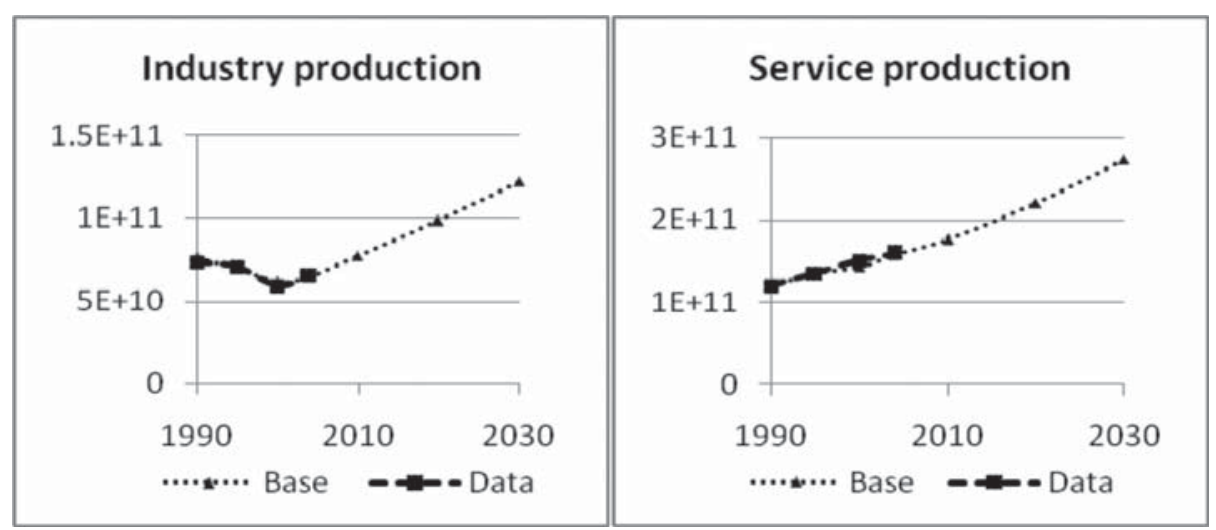

Figure 6: Comparing industry (a) and service (b) productions. 

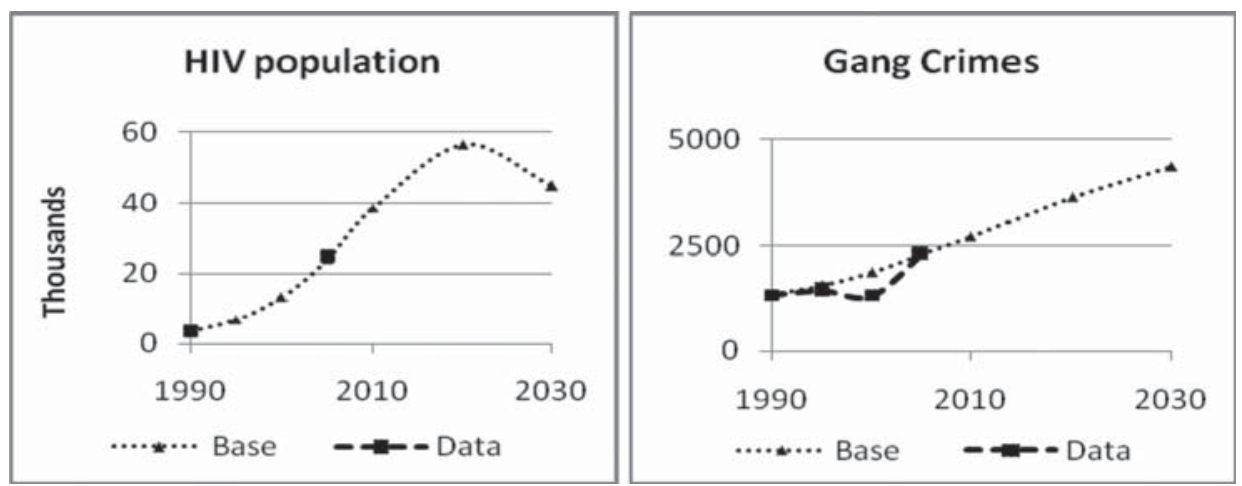

Figure 7: Comparing HIV population (a) and crime cases (b) with historical data.

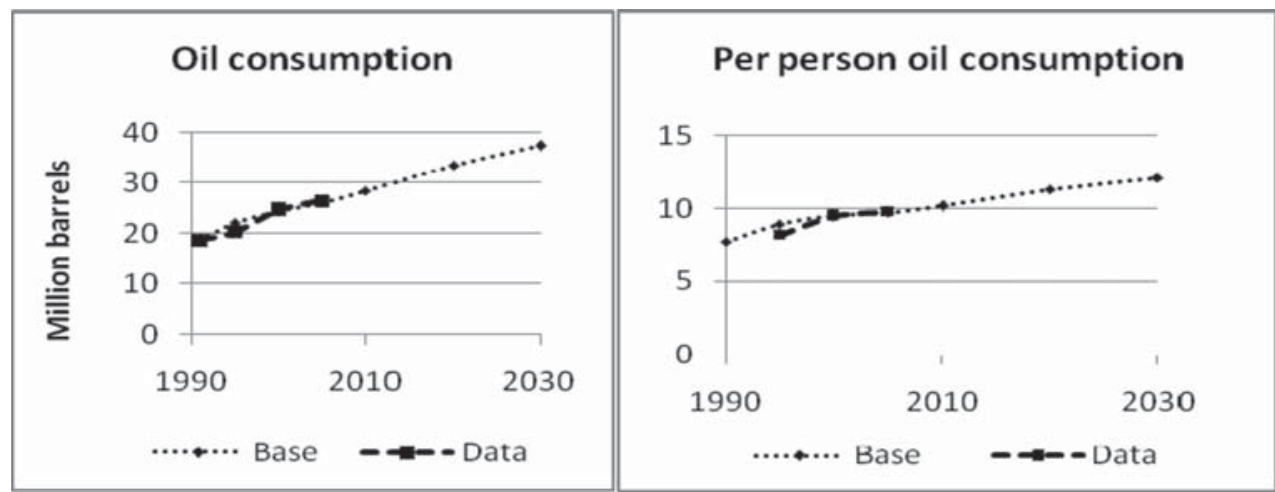

Figure 8: Comparing oil demand (a) and per person oil use (b) with historical data.

those infected (including babies through perinatal transmission), T21 Jamaica also includes the effects of HIV/AIDS on increasing the number of AIDS orphans, the life expectancy of the entire population, and overall labor productivity. In the case of violent crime cases, the indicator of gang related murders and shootings exceeded 2,000 in 2005, which is very high for a country with only 2.73 million people. The high crime rate could discourage tourism and foreign direct investment (FDI), both of which constitute indispensable factors in the growth of the economy.

On the natural resource and environment side, oil demand and the efficiency of its use present a major challenge. Jamaica's electric power is primarily generated from oil, and its vehicle fleet is increasing fast. Jamaica has not found any fossil fuel energy resources yet, so all its energy demand must be met by imports from an unstable and increasingly more expensive international oil market.

Oil import demand could approach 40 million barrels a year by 2030 (Fig. 8a), and oil use per person (in barrels per year) will continue to increase (Fig. 8b). While overall use efficiency in terms of millions of barrels per unit of GDP is expected to improve modestly, energy use per capita will increase. However, Jamaica may not be able to afford such a higher level of oil imports, especially if prices go up sharply in the near future; or even worse, it may not have access to import oil in times of shortages! Jamaica has to find a way to reduce its dependence on oil imports and increase its efficiency in using this resource. 
Another challenge which is bound to happen, but is rather difficult to predict and model, is related to the impacts of natural disasters. As global warming gets more severe, hurricanes are likely to become more frequent and more devastating. Based on the experience of earlier disasters and their impacts on production, government expenditures, etc., T21 Jamaica allows users to analyze the effects of possible future disasters by inputting the timing, magnitude, and frequency of such disasters. The model then generates their consequences in the projected scenario, based on the effects of similar disasters in the recent past. While it is not possible to predict when such disasters will happen, it is fairly certain that several will occur between now and 2030, so it is important to see what the impacts of disasters will be on Jamaica's prospects.

The above examples from the base run illustrate several of the key challenges Jamaica faces in order to achieve its strategic objectives. To deal with these challenges, Jamaica will have to introduce new policies and programs to accelerate its development in a balanced pattern that takes account of the impacts across all the social, economic, and environmental sectors.

\section{EFFECTIVE POLICIES TO ACCELERATE DEVELOPMENT: GOOD CHOICE SCENARIO}

From the Base scenario analysis, it is obvious that by continuing with business as usual policies, the ambitious goals of Jamaica to reach developed country status and to be 'the place of choice to raise families, live, work and do business' by 2030 will not be achieved.

Successful national development planning and implementation is a country specific endeavor which requires experience, creativity, hard work, and unselfish dedication from leaders in government, civil society, and academia. With different backgrounds and working at different positions, members of the team are bound to have different priorities and different ideas about how to achieve them. To plan effectively, they need to be able to work together, understand how different approaches work, and see what the full effects are across the country and beyond their specific sectors.

Looking at a typical example, it is highly likely that some would propose that the government spend more on education. If we examine this proposal closely, there will be further issues, such as:

1. When the education share in government budget is increased, some of the other expenditures must be cut. Which ones should they be? Or the government would have to increase its borrowing, which will add to its debt burden and future repayments; and

2. Once the education budget is increased, how should it be used? Building more schools, giving teachers a raise, involving more parents in school programs, or providing free textbooks?

There could be dozens of different proposals about how much more funds should be allocated to education and how they should be allocated. Under each proposal there could be multiple issues. Each proposal would have its own benefits and costs, and all the issues are connected to one another, directly or indirectly, forming a complex web of results that evolve over time. Such a complex system could make constructive dialogues and compromise agreement among all stakeholders difficult, or even impossible. And it is similarly difficult for decision makers to make well informed and objective choices when faced with alternative approaches and uncertainty about their outcomes.

The T21 model is an integrated tool that helps stakeholders understand the full effects of their and others' suggestions, because it demonstrates the results of different approaches across all sectors in a common and consistent framework. It provides direct comparison of overall consequences of the different proposals and thus enables more effective communication among the team members and compels them to think more broadly and in more depth. They not only propose their own ideas, but also have to think about all the possible side effects and feedback through other sectors. T21's transparency shows 
the results more broadly and encourages more thorough justification of proposals. It helps different stakeholders work out improved proposals that may reflect compromises to gain broader support.

At the next level, T21 is a tool to support the decision makers in arriving at their decisions: it is not meant to simply provide 'optimal solutions' for them to accept. Decision makers are faced with many challenges in considering different proposals from individual sectors and deciding which set will work the best to make progress towards a broad range of goals, not simply one or two. They need to be able to consider both their direct and indirect effects and how they might interact. Decision makers can use T21 both to examine and compare competing policy options within a sector and to examine the overall, integrated effects of sets of policies across sectors. This helps them come to agreement about the best strategic set of policies to achieve their goals.

It is quite clear from the experiments with sector policies that there is no single policy that will work satisfactorily to achieve Jamaica's goals. An integrated set of policies in multiple areas is needed to achieve desired development. The following set of policy choices emerged as highly effective in the initial testing and these choices are combined into the scenario 'Good Choice', to illustrate how T21 can help determine what policies are needed. To illustrate the benefits, this more comprehensive set of eight policies will be compared with scenarios of more narrowly focused policy options in Section 5.

\subsection{More government expenditures on education}

Currently, the government is spending about $30 \%$ of its non-debt expenditure on education, which is quite high compared with other countries. Practically, there is limited room for this share to increase. In the Good Choice scenario, we assume that this share will increase to $35 \%$ in 2008, and stay at this level through to 2030. Expenditures in all other areas will be reduced proportionally.

The major modeling issue is how effective the extra education expenditures will be. Since experts have proposed different ways to spend them but have not agreed on how to measure their effects, the T21 modeling team started from what experts all agreed: education quality needs to be improved. It is further decided that quality improvement in education will be measured by relative strength of human capital (measured by cumulative investment in education) against physical economic capital (cumulative economic investment). More detailed use of the T21 Jamaica model is being planned to determine how best to achieve these improvements. It is assumed that the human capital accumulated from the extra education funding, that is, invested in students will be twice as effective as economic capital, after these students enter into labor force [8].

Even with highly beneficial results of the extra expenditures on education, there is a time lag before the effects become visible in economic and social development. This lag reflects the time it takes the students to finish their education, get jobs, and occupy a larger portion of the work force. T21 takes account of these delayed effects to show how the improvements will emerge over time.

\subsection{More government expenditures on infrastructure}

Infrastructure includes networks of transportation, communication, energy, and water. It is vital for economic development and quality of life, and it needs to be expanded in the right places to sustain more rapid growth. Infrastructure takes time to build, and once construction is completed, it needs maintenance. Well established infrastructure attracts more investment and can contribute to higher labor productivity. T21 assumes that the government can direct new infrastructure (either publicly or privately built) to areas that will have the most benefits.

Currently, the government is spending about $7 \%$ of its available resources on infrastructure. We assume that this share will increase to $9 \%$ in 2008, and gradually increase to $10 \%$ by 2030 . 
Expenditures in all other areas will be reduced proportionally. T21 will also take account of the construction delays and the added maintenance costs of the additional infrastructure in illustrating its impacts on Jamaica's development.

\subsection{Attracting more remittances and FDI, and encouraging domestic savings}

Remittances are substantial in Jamaica, and have been growing fast. In 1990, they were equivalent to $3 \%$ of GDP. In 2005, they rose to $13 \%$ of GDP, and their real dollar amount rose by $500 \%$ over the 15 -year period (an average growth of $12.5 \%$ per year). Under favorable conditions, it is expected that remittances will continue to grow, though less than the surge in the 90s. We assume that during the 25-year period 2005-2030, remittances will increase by 3.8\% a year (compared with $2.2 \%$ used in the Base scenario).

FDI has also grown substantially in the past, roughly in parallel with remittances. With the right government policy achieving a low crime rate and healthy economy, FDI should grow further. During the 25-year period 2005-2030, it is assumed that FDI will increase by $4.5 \%$ a year (compared with $3.2 \%$ used in the Base scenario). This is entirely consistent with the expected improvements in the quality of the labor force and infrastructure.

The private savings rate has been high in Jamaica, reaching $32 \%$ in 2001. It is assumed that this rate will continue into the future and that the government will gradually reduce its borrowings from the private sector, allowing the portion of the private savings that goes into investment to rise.

\subsection{Informal economy development and conversion}

There is no reliable data about the size of the informal economy in Jamaica. Based on the 2005 Jamaica living conditions survey, it was estimated that, using the T21 model, the informal economy accounted for about $20 \%$ of formal GDP. It is assumed that the informal economy will continue to steadily grow, to $30 \%$ of GDP by 2030 , and half of it will pay a $10 \%$ value added tax by 2030 .

\subsection{Reducing HIV infection}

It is estimated in T21 that about $40 \%$ of Jamaica's sexually active population practice safe sexual behavior in 2005, and in the baseline scenario this fraction will increase to $65 \%$ by 2030 . With the Good Choice scenario, it is assumed that safe sexual behavior will become even more widespread (20\% higher than the baseline in 2008, and 50\% higher in 2030, if other conditions remain the same). With less people infected with HIV, and each HIV patient having less chance to infect other people, the HIV adult prevalence rate will be lower, and fewer people will die from AIDS. Total population, especially in working ages, will rise, and life expectancy will increase. Longer life expectancy means better health, and will contribute to increased productivity, but more people in the working age range could mean higher pressure on employment.

\subsection{Reducing crime}

The high crime rate is considered to be a major factor that discourages tourism and FDI, both important drivers of the Jamaican economy [9]. Many factors have contributed to the high crime rate, including unemployment, poverty, lack of effective community work, and inadequate law enforcement. It is assumed that effective community programs, based on current pilot programs, will be introduced 
and will reduce by $50 \%$ in 2030, the number of young males who become gang members, and that law enforcement will be strengthened. These measures are expected to reduce (also by 50\% in 2030) the access to guns and other weapons by gang members. Reducing crime will make increasing tourism and FDI easier and help raise the overall quality of life.

\subsection{Micro credit and reducing poverty}

For poverty reduction in the urban area, there is international evidence that developing more locally based and labor intensive businesses will provide more employment opportunities for the poor and also help develop a national class of entrepreneurs, some of whom may expand their enterprises to develop a national industrial base. Building on MI's experiences in other countries (Bangladesh and Mozambique), a Micro Credit sector was added to T21 Jamaica [10].

The Micro Credit Sector employs a process where the government, together with private matching funds, makes small, low interest loans and training available to entrepreneurs to start and operate their businesses. The model allows the government to allocate a small fraction of its expenditures to micro credit activities, including loans, training, and administration. Other government expenditures are reduced by the amount allocated to micro credit so as not to affect the overall budget deficit. It is further assumed that micro credit loans have a payback period of 3 years, and their default rates are related to interest rate, so the higher the interest rate, the higher the default rate. These assumptions can be modified to reflect different estimates.

Micro credit loans will finance small enterprise investments. It is assumed that the capital in small enterprises supported by the credit program will generate value added at the rate of $30 \%$ (every million JMD in capital will generate 0.3 million JMD annually in value added) and generate one employment position for every 140,000 JMD (in 1996 value, about \$4,000) of capital created. In the Good Choice scenario, $3 \%$ of government expenditures will be spent on micro credit programs, starting from 2008 , with $100 \%$ private matching funds.

It should be noted that in this and any other policy choice which increases certain government expenditures at the expense of reduced expenditures in other sectors, the short term reduction in the actual level of the other sector expenditures may be offset over time, as GDP (government revenue base) grows faster.

\subsection{Promoting growth with science and technology}

Investment in applied research can generate huge returns, if the right projects are selected. At present, a few applied research and development $(\mathrm{R} \& \mathrm{D})$ projects in Jamaica look quite promising in the areas of agriculture and pharmacy. If the government sponsors or supports a venture capital business, with strong private bank participation, to successfully promote the applied R\&D projects which are well fitted to Jamaica, stronger growth is likely. It is assumed that the government will allocate $2 \%$ of its available resource to selected R\&D, starting from 2008 , with private matching funds doubling the overall $R \& D$ fund size. It is also assumed that these projects have a success rate of $50 \%$, and that there is a delay for commercialization of 10 years. Once successful and commercialized, they are five times as productive as normal investment in industry. Private matching funds here and in micro credit will reduce private investment in all other sectors.

Figure 9 provides a high level graphic illustration of how the eight policy measures in Good Choice would affect Jamaica's social and economic development prospects. The four positive feedback loops illustrated are the source of economic growth in many countries. However, these mechanisms might 


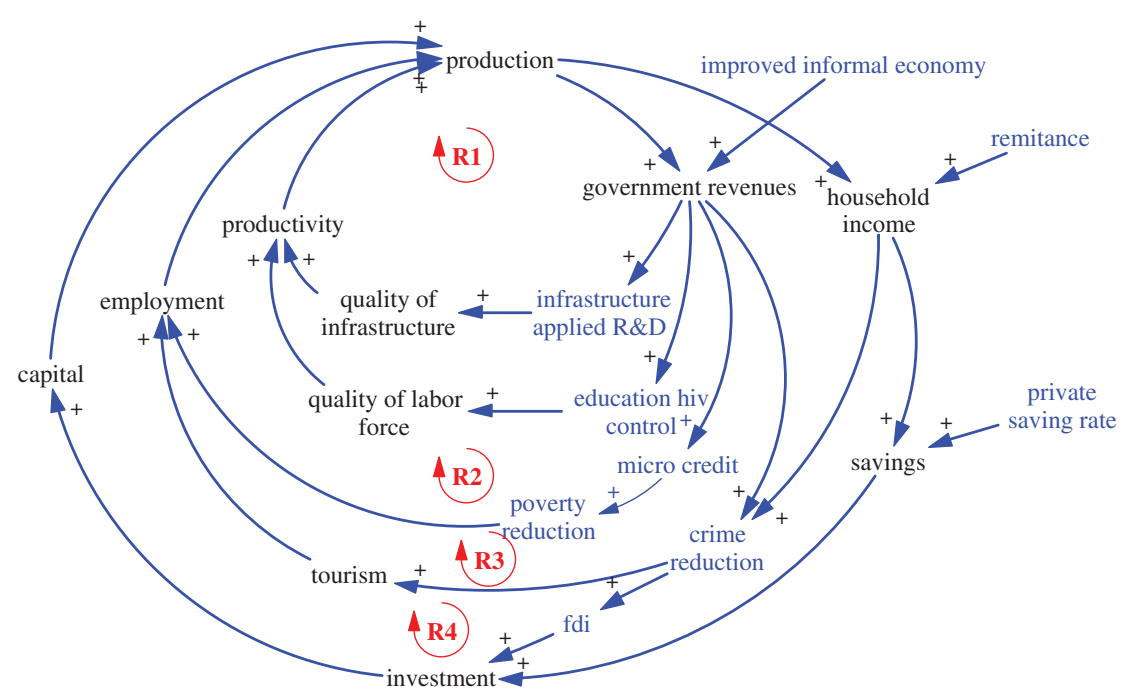

Figure 9: High level causal relationships of the Good Choice scenario.

work slowly due to the time delays involved in the accumulation of human resources and in the creation of proper infrastructure.

There are negative feedback loops as well. When the government increases its expenditures on infrastructure and education, other government expenditures will be cut, and possibly having negative effects on production. When HIV infection is under control, less working age people will suffer from and die of AIDS. Then the labor supply will be higher, and so will unemployment. These feedback loops are included in T21. The actual model is much more complex with more detailed relations and feedback loops. But this figure clearly demonstrates how T21 takes more interactions across the economic, social, and environmental sectors into account than typical sector models.

\section{NARROWLY FOCUSED SCENARIO AND EXTERNAL SHOCK SCENARIO}

The scenario below, called 'Narrowly Focused', includes three socially oriented policy measures that are likely to be the goal of many policy makers:

1. Increase the share of education expenditure in the government budget from $30 \%$ to $35 \%$;

2. Increase the share of health care expenditure in the government budget from $15 \%$ to $18 \%$; and

3. Increase the share of welfare (poverty assistance) expenditure in the government budget from $0.4 \%$ to $4 \%$ to provide food, shelter, and medical assistance to the poor.

Another fact that makes long-term national planning difficult is that there are things beyond the control of decisions makers that affect a country's prospects, such as international oil price changes, or national disasters, like hurricanes. In the 'Disaster' scenario, it is assumed that:

1. International oil price will gradually rise to $\$ 150$ per barrel in real terms by 2030 (as against $\$ 87$ per barrel in 2030 for the base scenario); and

2. Hurricanes, as strong as Hurricane Ivan in 2004 , will hit the country once every 5 years starting from 2007. 


\section{COMPARISONS OF THE FOUR SCENARIOS}

The four scenarios are Base, Good Choice (G-Choice), Narrowly Focused (N-Focused), and Disaster. We can use the graphs generated by T21 to demonstrate the different trends of major indicators from these four scenarios. These indicators are grouped in the major sectors of interest. Graphs can be compared for any variable in the model over the entire projection period. Numeric values of these indicators for all scenarios are also provided by the T21 model and can be transferred to Excel for more detailed analysis.

Economic indicators: real GDP from the Good Choice scenario will be $76 \%$ higher than the Base scenario by 2030. The Narrowly Focused scenario will perform a bit below the Base as it has fewer contributions to increasing growth; and the Disaster scenario will be 18\% below the Base GDP by 2030 due to the impact of storms and higher oil prices. This comparison is shown in Fig. 10.

Government budget: due to a larger tax base (GDP), government revenues from the Good Choice scenario will be much higher than from other scenarios, as shown in Fig. 11a. It is interesting to note in the next graph of Fig. 11b, that although the Narrowly Focused scenario has higher shares of government expenditures in education, the actual expenditures in this sector for this scenario is only slightly higher than the Good Choice scenario for the first 5 years or so. After 2010, the actual level of government expenditures in education in the Good Choice scenario exceeds those in the Narrowly Focused scenario due to the higher GDP level and resulting tax revenues in the Good Choice scenario. Similar pattern happens in health care expenditures (not shown here). The Disaster scenario performed worst among the scenarios.

Population and poverty: Fig. 12 shows the life expectancy at birth and proportion of population living under poverty. Due to higher life expectancy from the Good Choice scenario, total population for the scenario is also higher (not shown here).

Unemployment: total employment and unemployment rate are shown in Fig. 13.

The Good Choice scenario also generates better results in other social indicators, including access to basic health care, adult literacy rate, the crime rate, and the HIV/AIDS adult prevalence rate.

Environmental indicators: this group includes land use, water demand, access to safe water, and emissions (which is discussed in the next group).

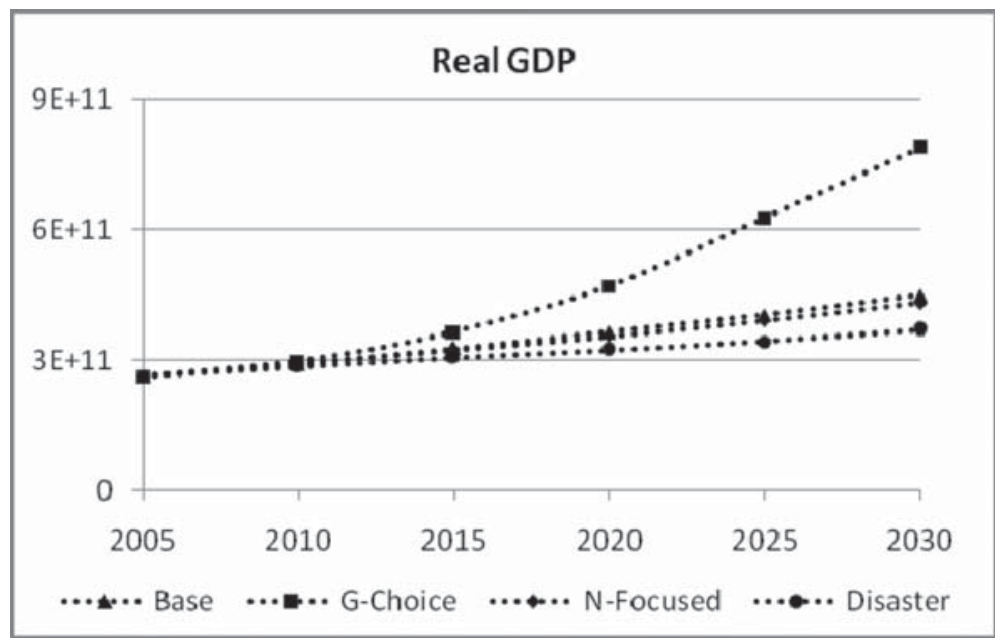

Figure 10: Real GDP comparison among the scenarios. 

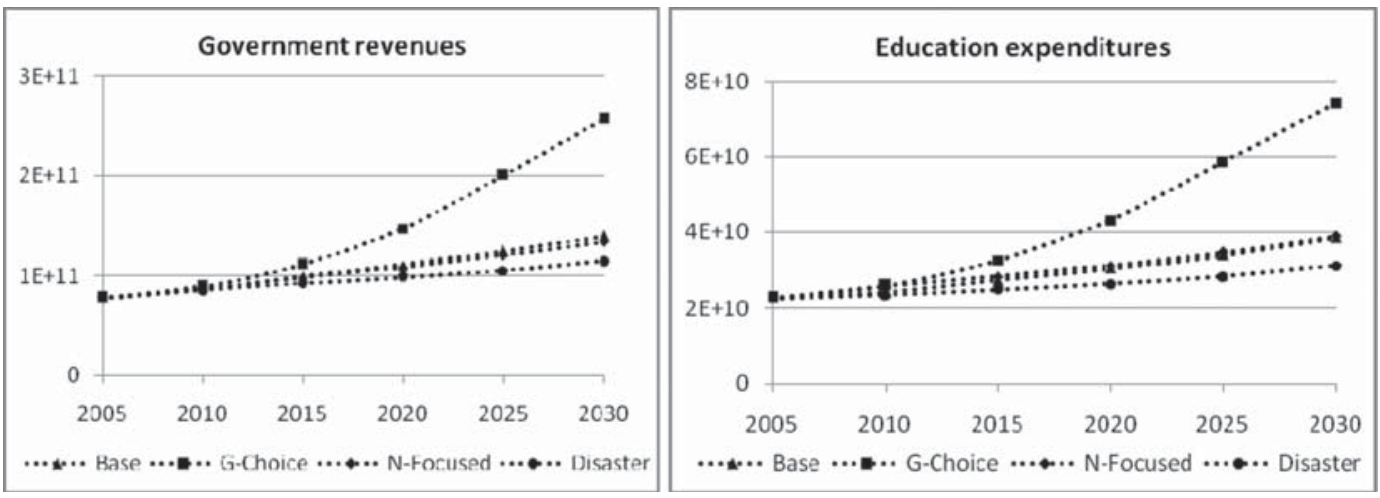

Figure 11: Government revenues (a) and public expenditures (b) in education.
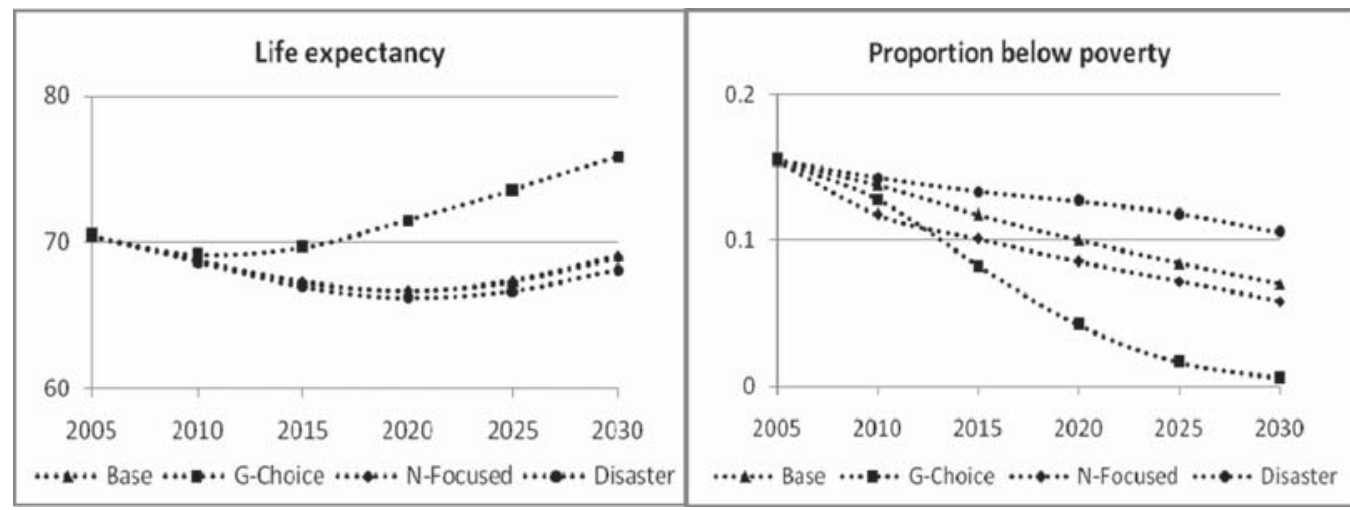

Figure 12: Life expectancy at birth (a) and proportion below poverty (b).
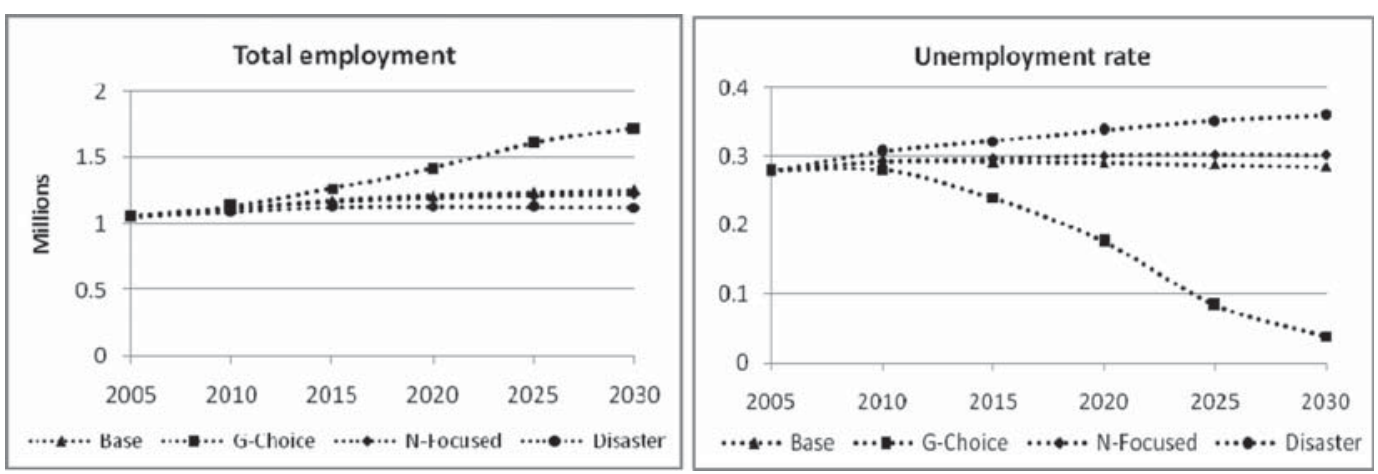

Figure 13: Employment (a) and potential unemployment (b) rate. 
Land in Jamaica is divided into agriculture land, commercial and residential land, forest land, and other land. Agricultural land demand is related to yield: the higher the yield, the smaller the amount of land required. The Good Choice scenario generates better quality of labor and higher technological progress, so its yield is the highest; while land demand is the highest in the Disaster scenario due to yield decline from storm damage. Land for commercial and residential construction is related to economic and population sizes, so the Good Choice scenario, which has larger population and higher GDP, has the biggest demand. Forest land for the scenarios does not show big differences. The sum of all the land sizes stays constant over time.

Due to higher income and higher GDP in the Good Choice scenario, its residential water demand and industrial water demand will be higher than other scenarios.

Access to safe drinking water is related to water pollution, income, and government expenditures in infrastructure. Water pollution in surface water in T21 is represented by BOD concentration and comes from three sources: sewage, agriculture, and industry. With the Good Choice scenario, higher GDP leads to higher pollutants from industry. But higher GDP also leads to higher income, which makes bottled water and treated water more affordable. Higher income and higher government infrastructure expenditure increase the coverage of adequate family sanitation, which reduces sewage pollutants. All these factors combined, the Good Choice scenario generates the highest access to safe water.

Energy demand and $\mathrm{CO}_{2}$ emission indicators: electricity demand will exceed 6 billion $\mathrm{KWh}$ in the Base scenario, and will approach 10 billion KWh for the Good Choice scenario. Annual oil demand will increase in a similar pattern: over 37 million barrels for the Base scenario and about 60 million barrels for the Good Choice scenario. $\mathrm{CO}_{2}$ emission from fossil fuels will grow proportionally. As Jamaica has not found any fossil fuel reserve, all the oil demand will have to be met by imports. Thus, international oil price and oil availability in the future will be a big risk factor for Jamaica. This demonstrates the trade offs of the Good Choice scenario: while it will generate substantial growth, it will place Jamaica at higher risk in relation to energy prices. To achieve stable and balanced development, Jamaica will have to improve its energy use efficiency, enhance energy conservation, and find alternative sources of energy.

Human Development Indicator (HDI) and Millennium Development Goal (MDG) indicator: T21 includes HDI [11] and many MDG indicators. As in other areas, the Good Choice scenario produces the best results. But it is important to note that the poorer results from the Disaster scenario indicate that bad external factors pose a risk to any option followed, and some precautionary measures, including insurance, would be desirable.

With the above groups of indicators, we have compared the performances of the four scenarios. It has shown that a broad range of good policy measures can make a huge difference for the future development prospects of Jamaica. But even a well designed set of policies, such as those used in the Good Choice scenario, can have its costs, such as increased energy dependency. The T21 model helps us to better understand and quantify all the benefits and costs. It also shows that to achieve an overall strategic target, such as Jamaica's for 2030, it requires coordinated programs across a number of sectors to generate more growth, make sure that the benefits are widely distributed, and guard against risks of possible external factors.

In the actual application of the model, many more scenarios are tested. It would be useful to include the external disasters in the Good Choice options to see how the risks would affect the desirable policy choices. Incorporating the disaster risks into the desirable policy sets would help identify the kinds of precautionary measures needed.

\section{APPLICATION OF T21 TO JAMAICA LONG-TERM PLANNING}

Jamaica has had a long history of development planning, commencing in 1947 when the first 10 year plan was developed. Subsequently, there has been one additional 10 year plan, and three 5 year 
plans, with various gaps without national plans. Despite its planning, the country has failed to sustain rapid economic growth.

In the process of formulating the first 25 year (2006-2030) national development strategy, the PIOJ evaluated the previous plans to determine their weaknesses. The following factors have emerged as major weaknesses:

1. Short-term horizons: the plans in the past were developed around the life span of the Government, and thus were not strategically focused on long-term development needs;

2. Inadequate implementation and monitoring framework: there were weak synergies among goals, indicators, and the budget allocations. The institutions that were given the mandate to implement and monitor the plans did not have the capacity to effectively undertake their functions; and

3. Limited buy-in, ownership, and involvement by the society: there was limited involvement of non-state actors in the planning process, thus the plan was not seen as Jamaica's plan, but rather that of the party running the government.

To address some of these weaknesses, the PIOJ has adopted a three pronged approach for the current planning process which include: (1) preparing a long-term National Development Plan ( 25 years) to 2030; (2) developing an integrated national planning model (T21 Jamaica) which is responsive to the changing structure of the economy; and (3) Ensuring a broad based collaborative approach to planning in the early stage of the planning process.

The T21 Jamaica model is being used in the Jamaica national planning process in the following ways:

1. Garnering support: the T21 model is used to garner support from both state and non-state actors by involving them in the planning process from its formulation stage. The T21 model allows different institutions to see the impact of their programs and helps identify areas in which different institutions can complement each other. Their involvement also contributes to refining the model, as they often bring new insights that refine or expand the key relations in the model.

2. Facilitating consultation: the T21 model allows the Task Forces to transparently articulate the implications of their plans to the groups who implement and monitor the national development plan.

3. Simulating scenarios: the Task Forces can run different scenarios to see which strategies will allow them to achieve the desired results most effectively and the implications of their plans for the economy, the society, and the environment. This helps identify mitigating measures to offset likely negative effects.

4. Integrating Sector Plans: the T21 model plays a central role in integrating the 30 different sector plans. Resource constraints will prevent simultaneous implementation of all sector plans; some will have to be phased in. T21 allows the Government to see the implications of different combinations of policies, better understand how to best phase them, and estimate how long it will take to implement the policies and to see their results.

5. Raising the level of dialogue: the ability of T21 to run different scenarios on a 'non-partisan' basis raises the level of dialogue in the society as the deliberations on national developmental issues will be grounded in a consistent framework. It also provides a means to deepen the discussion of policy advisors and stakeholders as they analyze the implications of different policy scenarios.

Once the strategic plan is agreed and implemented, PIOJ and others can select the key indicators and use T21 to monitor progress, based on the scenario of the policies chosen in the strategy. It will 
help highlight where policies are attaining their goals, and detect where shortfalls indicate that more attention may be needed, or policies revised in order to reach the selected goals.

\section{FURTHER RESEARCH AND SUMMARY REMARKS}

T21 is a work in progress: each time it is customized to a specific country, new issues emerge that demand modifications or additions in order to address the specific needs and conditions of the country. The modeling team including MI and the country experts, works together to expand the model to meet the demands. In T21 Jamaica, the crime sector and the R\&D sector are newly developed.

Once the country team is fully trained and the T21 model is operational, new demands continue to emerge that require further changes in the country T21 model. For Jamaica, this is currently being managed by PIOJ. The 30 Task Forces will raise issues and propose strategies, not all of which are included in T21. So the technical team at PIOJ will work with the Task Forces to modify and expand T21 to incorporate these issues for analysis by the Task Forces. MI will provide additional advice as needed.

It should be noted that results from T21 are not predictions. They are scenarios that help decision makers better understand possible consequences of policies or shocks, and then plan better to achieve the benefits and manage the costs. The results presented above are based on the latest version of T21 Jamaica.

It is hoped that this exercise will be a test case for other Caribbean countries as well as for all SIDS (Small Island Developing States) that face similar challenges and need similar tools for supporting their long-term decision making.

Areas for further research and expansion of T21 Jamaica are being identified in the national planning process, such as the costs and benefits of developing sugarcane ethanol and the effect of tariff liberalization. MI and PIOJ will continue to share their knowledge and modeling skills in these areas.

In addition to the material in this paper, the reader can actually try a number of alternatives of your own choice. You can download the model from MI's webpage at www.millenniuminstitute.org, install it on your PC, and then run it. The model gives users the flexibility to combine multiple policies and shocks, and the results can be displayed in either graphical or table (numeric) form.

\section{REFERENCES}

[1] World Bank World Development Indicators 2005, available at http://www.worldbank.org/

[2] PIOJ, Statistical Office of Jamaica (STATIN), Jamaica Survey of Living Conditions 2005 (jointly published by PIOJ and STATIN), 2006.

[3] PIOJ, Jamaica's National Development Plan 2030, A Situational Analysis of the State of the Natural Environment and Urban and Regional Planning in Jamaica, first draft, PIOJ, 2006.

[4] Pedercini, M., Sanogo, S. \& Camara, K., Threshold21 Mali: system dynamics based national development planning in Mali. Proceedings of the 24th International Systems Dynamics Conference, Boston, USA, 2007.

[5] Qu, W., Barney, G. \& Symalla, D., Applications of linkages in THRESHOLD 21: a national integrated development model. Proceedings of the 17th International Systems Dynamics Conference, Bergen, Norway, 2000.

[6] Qu, W., Chu, T., Barney, G. \& Shilling, J., Challenges facing China in the next 15 years. Proceedings of the International Systems Dynamics Conference, Shanghai, China, 2005.

[7] STATIN, Demographic Statistics 2005, STATIN, 2006. 
[8] The World Bank, Expanding the Measure of Wealth, Indicators of Environmentally Sustainable Development, World Bank, 1997.

[9] Wilks, J., Qu, W. \& Pedercini, M., A dynamic analysis of organized crime in Jamaica. Proceedings of the 24th International Systems Dynamics Conference, Boston, USA, 2007.

[10] Qu, W. \& Barney, G., A model for evaluating the policy impact on poverty. Proceedings of the 19th International Systems Dynamics Conference, Palermo, Sicily, Italy, 2002.

[11] United Nations Development Program, Human Development Report 2006, available at http:// hdr.undp.org/hdr2006/report.cfm 